\title{
Nurturing Healthy India
}

\author{
Swati Dave* \\ Department of Dietitian, ESIC Model Hospital, India \\ *Corresponding Author: Swati Dave, Department of Dietitian, ESIC Model Hospital, India.
}

Received: August 09, 2019; Published: October 11, 2019

DOI: $10.31080 /$ ASNH.2019.03.0500

Complimentary feeding aka weaning is an exciting time for both mother and child. It is primarily a huge step towards whole new world of family dietary patterns considering various food tastes \& textures thereof. Making appropriate weaning food choices for child during his/her first year of life is very essential, too. As more growth occurs during the first 1000 days than at any other time in child's life. It's important to feed them a variety of healthy foods at the proper time. WHO recommends exclusive breastfeeding until 6 months followed by weaning. Infants thrive on breast milk alone up to six months of life and their growth rate during this period is satisfactory. After six months, increasing needs of calories and protein of growing children cannot be met by diminishing output of mother's milk. Milk is also a poor source of vitamin C \& supplementation with fruit juice is essential. Iron stores in liver of the infant would last only upto 4-6 months. Hence iron rich foods should be given atleast from six months onwards. Weaning food should provide atleast 10 per cent of the energy as protein. Starting good eating habits at this early stage will help set healthy eating patterns for life.

6 months to 1 year: Breast feeds + supplementary feeds to continue or full strength milk ( 4 hourly schedule, 4-5 feeds per day, 2-3 times a day).

Now a days for working lactating mothers, pressure of returning back to work after child birth is playing crucial role in early inception of weaning which calls for a lot of help \& family support. Buying \& feeding readymade solutions to the little ones has become a trend. On top of it mothers are tempted to add salt or sugar to baby's food, however bland. This is the time when you need to refer a qualified dietitian nutritionist to discuss a proper diet according to child's age.
- When? - After 6 months.

- Why? - Increased nutritional requirements for proper growth \& development.

- How and What? - Start with a single ingredient at a time, wait for its acceptance, then gradually add other foodstuffs e.g. vegetables, fruits or dals to the diet, based on the child's acceptance.

\section{Volume 3 Issue 11 November 2019 (C) All rights are reserved by Swati Dave.}

